\title{
Expectant Management of Ectopic Pregnancy - A Case Report
}

\author{
QE FORHAD ${ }^{\mathrm{a}}$, K KHAN ${ }^{\mathrm{b}}$
}

Summary:

A patient with suspected ectopic pregnancy was managed successfully with expectant approach using serial serum ${ }^{2}$ hCG monitoring. Expectant management can be a useful

\section{Introduction:}

Ectopic pregnancy is a disaster in human reproduction. It is one of the most important causes of death during the first trimester of pregnancy. Ectopic pregnancy is more threatening for women than normal vaginal delivery and induced abortions ${ }^{1}$. If it is not diagnosed and treated expeditiously, it may also take the life of the mother or at the very least, compromise her future ability to reproduce.

Ectopic pregnancy effects approximately 2\% at all pregnancies ${ }^{2}$. Currently over $90 \%$ of ectopic pregnancy can be visualized on Transvaginal scan (TS). This means that early ectopic pregnancy can be detected in asymptomatic women ${ }^{3}$ by TVS and the rapid immunoassay of serum ${ }^{2}$ hCG. The advent of modern diagnostic technique, the treatment modalities of ectopic pregnancy has changed dramatically.

\section{Case Report:}

A 30 years old housewife was referred to our hospital on May 08, 2008 with complains of intermittent pervaginal spotting over the preceding 3 weeks. Her last menstrual period was on February 12, 2008. Pregnancy test was positive at 6 weeks of gestation. This was her planned pregnancy. Ultrasonography was done - at 10 weeks of her gestation outside our hospital. It

a. Dr. Quorrata Eynul Forhad, Assistant Professor, Gynae \& Obs - Shahabuddin Medical College \& Hospital.

b. Dr Kohinoor Khan, Professor \& Head of the Department, Gynae \& Obs - Shahabuddin Medical College \& Hospital.

Address of Correspondence: Dr. Quorrata Eynul Forhad, Assistant Professor, Gynae \& Obs - Shahabuddin Medical College \& Hospital. Received: 25 February, 2009

Accepted: 11 June, 2012 form of treatment for ectopic pregnancy in selected patients.

Key words: Pregnancy, ectopic pregnancy expectant.

(J Bangladesh Coll Phys Surg 2012; 30: 170-172)

did not show any intrauterine gestational sac but there was presence of an adnexal mass, the size of which could not be mentioned.

She had complicated past obstetric and gynecological history. In 2001, she had a ruptured right tubal pregnancy and right sided salpingectomy was performed. There were extensive pelvic adhesions with pelvic endometriosis which were noted in the operation note of the patient.

On admission, her general condition was stable. The abdomen was soft and non tender. Some brownish old blood was seen on vaginal speculum examination and the cevical os was closed and non tender.

The hemoglobin level was $11 \mathrm{gm} / \mathrm{dl}$. Transabdominal and transvaginal ultra sonogram were performed with the following findings: the uterus was bulky with thick endometrial echo. There was no evidence of an intrauterine pregnancy. A complex mass measuring 4 $\mathrm{cm}$ in diameter was seen around the left adnexa. Vascular flow signals were detected within and surrounding the mass. There was no free fluid in the pouch of Douglas. So, clinical diagnosis was in favour of tubal pregnancy. Serum ${ }^{2} \mathrm{hCG}$ was done which revealed increased value. (In May 09, 2008 ²hCG - $7092 \mathrm{miu} / \mathrm{ml}$ ).

But the patient remained asymptomatic apart from minimal vaginal spotting and there was no sign of ruptured ectopic pregnancy. So there was no option for surgical treatment. Only follow-up of the patient was done by serial ${ }^{2} \mathrm{hCG}$. There was a falling level of serum ${ }^{2} \mathrm{hCG}$ over 48 hours from $7092 \mathrm{miu} / \mathrm{ml}$ (may 09) to $3915 \mathrm{miu} / \mathrm{ml}$ (may 11). In view of the above finding, and those at previous operation, expectant management was planned. 


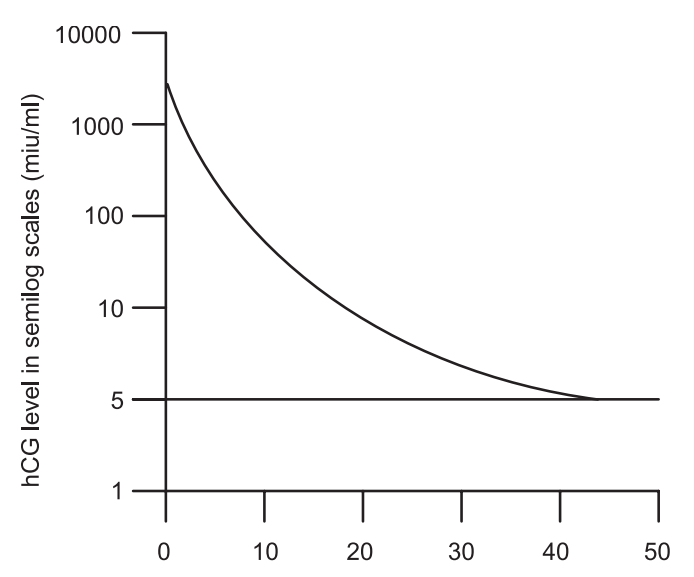

Fig-1: Serial hCG level versus number of days after initial diagnosis.

She had to come back regularly for follow up with ${ }^{2 h C G}$ monitoring. We had to explain the risk of ruptured ectopic pregnancy and the need for emergency surgical intervention if this occurred. She was advised to come back immediately if there was any abdominal pain or vaginal bleeding.

She then remained asymptomatic and the serum ${ }^{2 h C G}$ level decreased to $24 \mathrm{miu} / \mathrm{ml}$ on June 04, i.e. day 28 of her initial diagnosis (Fig- 1). Menstruation returned on the same day. The serum ${ }^{2} \mathrm{hCG}$ level decreased further to less than $5 \mathrm{miu} / \mathrm{ml}$ ( ${ }^{2} \mathrm{hCG}$ level less than $5 \mathrm{miu} / \mathrm{ml}$ is considered to be normal for the non pregnant status) on June 24, i.e. day 48 after the initial diagnosis. A follow up ultra sonogram was performed on June 29 (Day 53). The decrease in the size of the mass could still be seen in the left adnexa, but no vascular flow signal was detected within or surrounding the mass.

\section{Discussion:}

Early diagnosis of unruptured ectopic pregnancy has become more common with the improvement of the diagnostic tools including radioimmunoassay of hCG (human chorionic gonadotropin) and transvaginal sonography. As a result, apart from traditional surgical treatment of ectopic pregnancy, medical treatment (e.g. methotrexate, prostagladins) and even expectant management are possible in well selected patients.

The rationale of expectant management is based on the observation that spontaneous resolution of ectopic pregnancy can occur with preservation of tubal patency.

This was first reported by Lynd in $1995{ }^{4}$.Depending on the selection criteria, the percentages of patients with ectopic pregnancy that are suitable for expectant management vary from $20 \%$ to $29 \%{ }^{5-8}$.

The most common criteria include:

1. No symptom or sign of rupture or acute bleeding.

2. A falling level of serum ${ }^{2} \mathrm{hCG}$ at a 48 hours interval.

3. The diameter of the suspected ectopic pregnancy $<4 \mathrm{~cm}$ shown on the pelvic ultrasonogram.

Our patient fulfils the first 2 criteria although a complex adnexal mass measuring $4 \mathrm{~cm}$ in diameter was shown by the pelvic ultrasonogram. We postulated that this size might have been due to preexisting tuboperitoneal adhesion and the size of the suspected ectopic pregnancy was most probably less than $4 \mathrm{~cm}$. The persistence of adnexal mass though in decreased size by the follow up ultrasonogram on day 53, even when the hCG level returned to normal supported this postulation. The disappearance of vascular flow signal within and surrounding this mass was compatible with resolution of the tubal ectopic pregnancy inside a complex mass of tuboperitoneal adhesions. Further follow up ultrasonogram will be performed.

Trio in 1995 presented the first report evaluating the ability of the hCG levels and sonographic finding to predict successful expectant management ${ }^{9}$. The following factors were identified.

1. An initial hCG level $<1000 \mathrm{miu} / \mathrm{ml}$ appeared to be the best independent predictor of a spontaneous resolution of ectopic pregnancy.

2. Ultrasonographic finding at the time of diagnosis did not seem to have any individual predictive value after controlling the initial hCG level and the trend in hcG levels.

In our patient, the initial hCG level was $7092 \mathrm{miu} / \mathrm{ml}$. Expectant management was adopted because we believed that the trend in hCG levels, particularly the decrease in the first 48 hours time interval was more important than the absolute value of the initial hCG level. The absolute hCG level would depend on the radioimmunoassay that was used and on which international standard it is calibrated against. Our patient had an acceptable decrease in hCG level (Fig-1) despite the initial hCG level being greater than $1000 \mathrm{miu} / \mathrm{ml}$.

The benefit of expectant management of ectopic pregnancy is the possibility of avoiding invasive surgical 
treatment (laparoscopy/laparotomy). The main disadvantage of expectant management is that of rupture of ectopic pregnancy. Other disadvantages of expectant management include the risk of additional tubal damage and blood loss, the need for an emergency operation, the cost of serial hCG measurements and ultrasonograms and the emotional cost from the anxiety of waiting for the spontaneous resolution of the ectopic pregnancy. As a result we recommend that a substantially favourable risk: benefit ratio has to be demonstrated before the expectant approach is to be adopted.

With successful expectant management the patient remains clinically stable and decreasing hCG levels with no ultrasonographic evidence of an enlarging adnexal mass. The waiting period ranges from 5 to 51 days $6,9,10$ and the success rate of expectant management ranges from $46 \%$ to $92 \%{ }^{5,8,11}$.

\section{Conclusion:}

Adequate explanation to the patient and judicious follow up of the patient are the essential components for the expectant management of ectopic pregnancy. The advent of modern diagnostic modalities has changed the clinical scenario of ectopic pregnancy from one possible disaster to one potential success. So, in conclusion, expectant management can be a useful form of treatment for ectopic pregnancy in selected patients.

\section{References:}

1. Cunningham FG, Gant NF, Leveno KJ, Gilstrap LC, Hauth JC, Wensform KD. Williams obstetrics, zist ed, Mc GrawHill, Whitridge Williams, 2001; 883-910.

2. Ectopic Pregnancy-United States; 1990-1992. Morbid Mortal, Wkly Rep. 1995-(Jan27); 44(3); 46-48.

3. Timor- Tritsch IE, Yeh MN, Peisner DB, Lesser KB, Slavik TA.

4. Lund JJ. Early ectopic pregnancy treated nonsurgically. J.Obstet Br. Empire 1995; 62: 70-76.

5. Shalev E, Romano S, Peleg D, Bustan M, Tsabari A. Spontaneous resolution of ectopic tubal pregnancy; natural history. Fertil Steril 1995; 63(1): 15-19.

6. Ylostalo P, Caccialore B, Sjoberg J, Josimovic JB. Expectant management of ectopic pregnancy. Obset Gynecol 1992; 80: 345-348.

7. Garcia AJ, Aubert JM, Sama J, Josimovich JB. Expectant management of presumed ectopic pregnancy. Fertil Steril 1987; 48: 395-400.

8. Femandez H, Rainhom JD, Papiemik E, Bellet D, Frydman R. Spontaneous resolution of ectopic pregnancy. Obstet Gynecol 1988; 71: 171-174.

9. Trio D, Lapinski RH, Strobelt N, Ghidini A, Picciolo C. Prognostic factors for successful expectant management of ectopic pregnancy. Fertil Steril 1995; 63: 469-472.

10. Ylostalo P, Cacciatore B, Korhonen J et al. Expectant management of ectopic pregnancy. Eur J Obstet Gynecol Repord Biol 1993; 49: 83-84.

11. Mashiach S, Carp HJA, Serr DM. Nonoperative management of ectopic pregnancy. J Reprod Med 1982; 27: 127-132. 